\section{Densidad de desarrollo alta y baja en Puerto Rico}

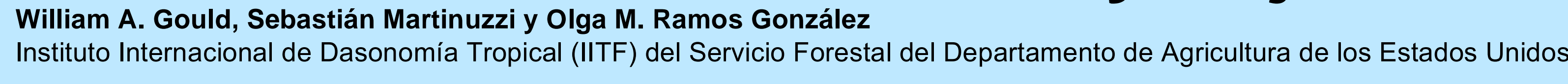

$=0$

$-3$

a. Dosectore
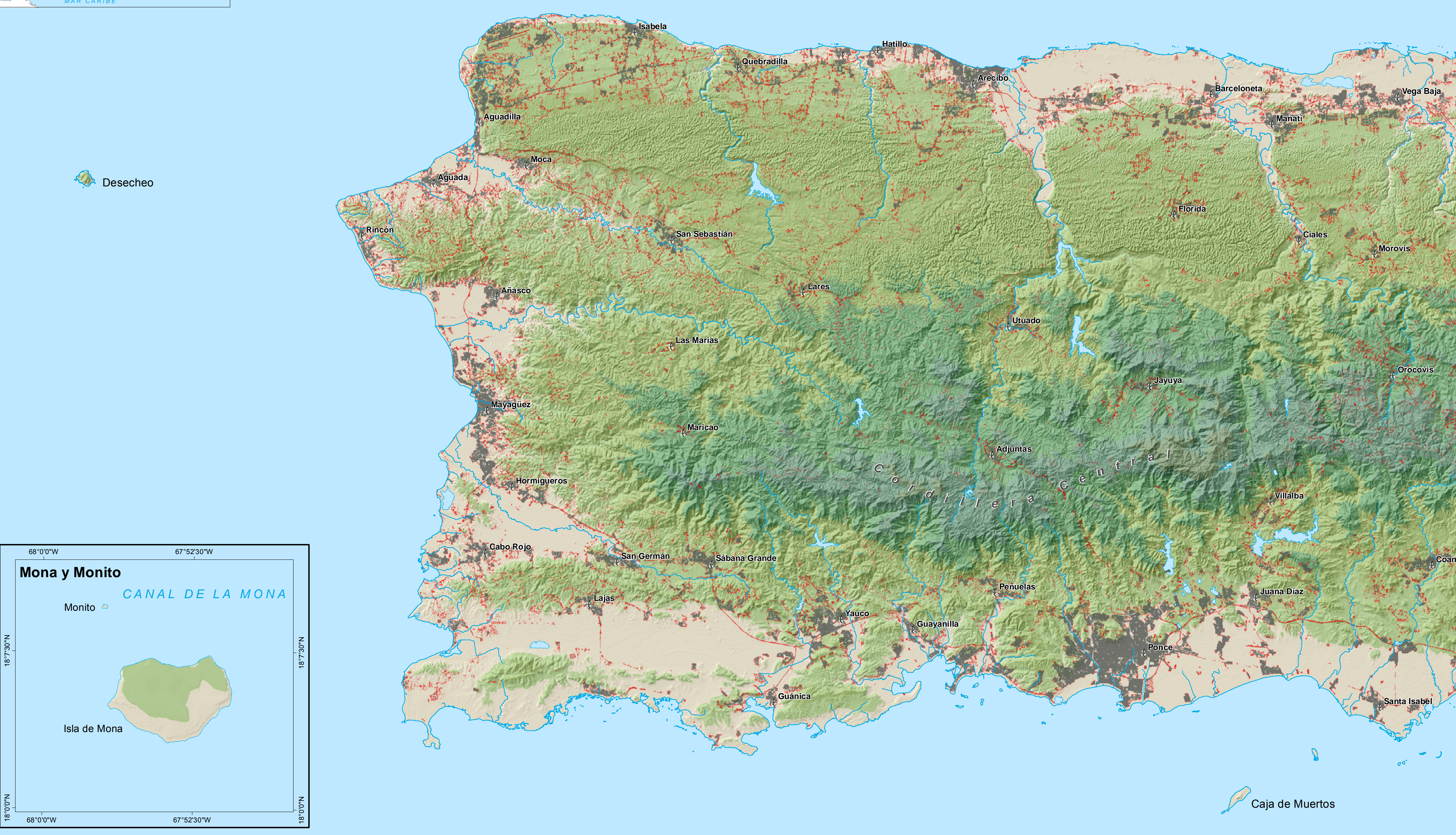

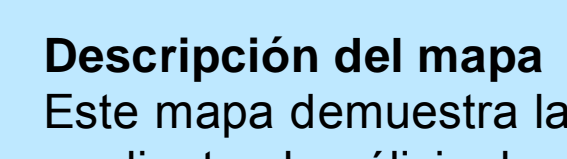

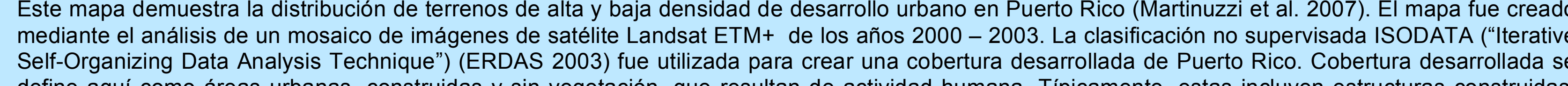

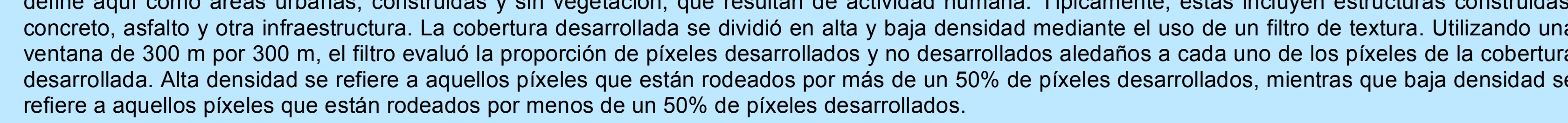

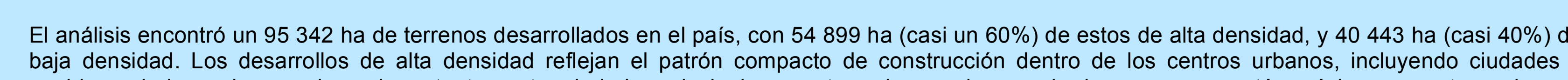

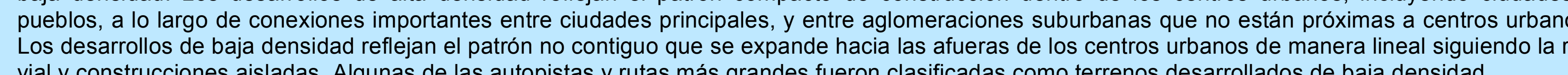

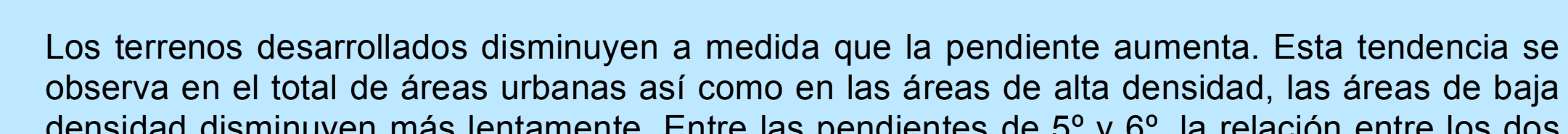

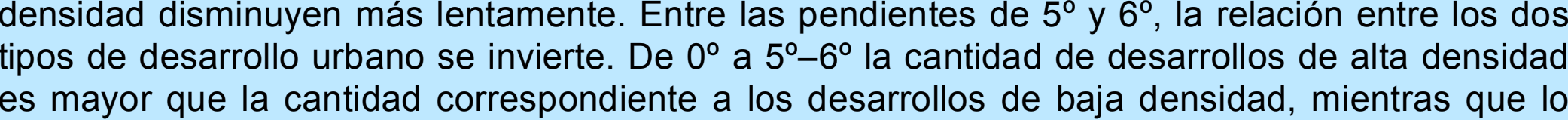

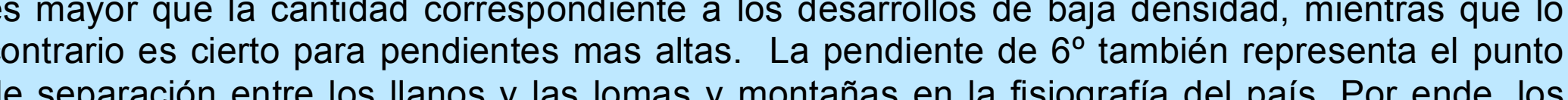

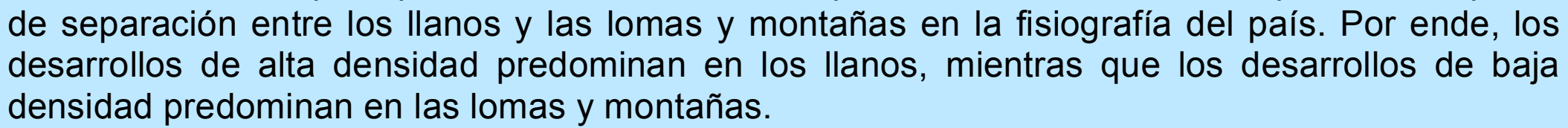

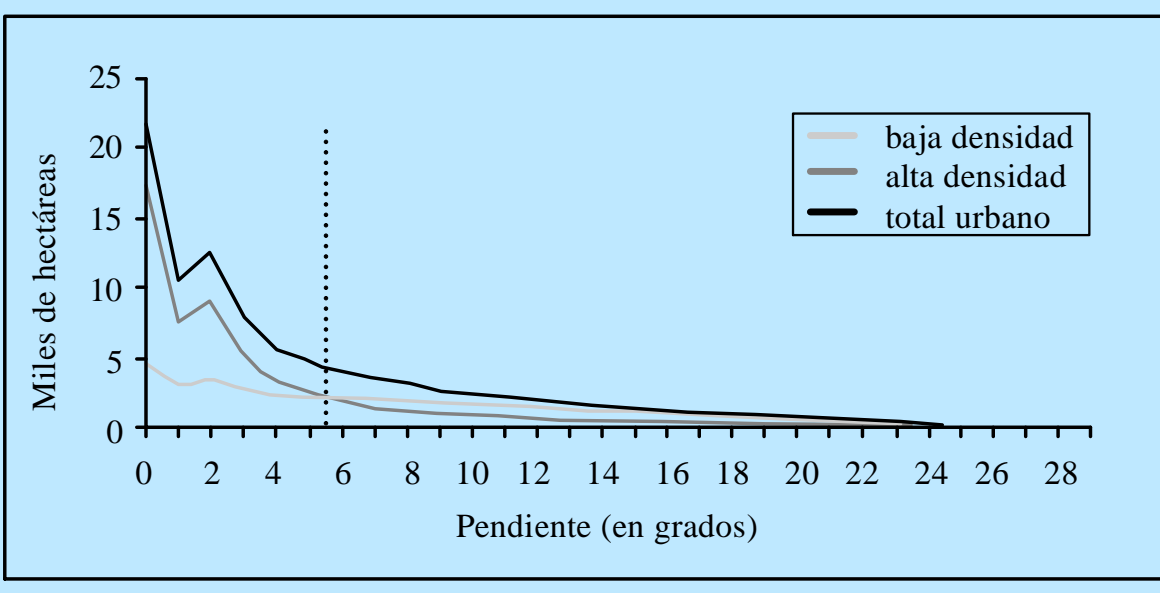

E 2
USDA UAS.

Proyecto de Análisis Gap de Puerto Rico

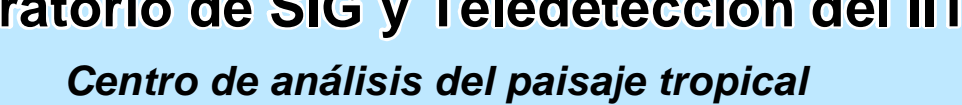

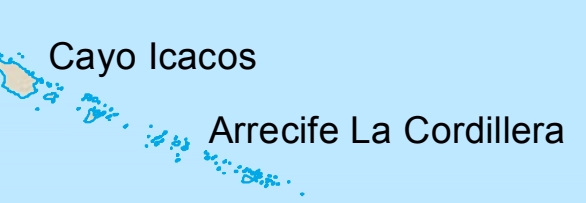

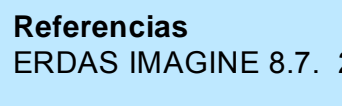

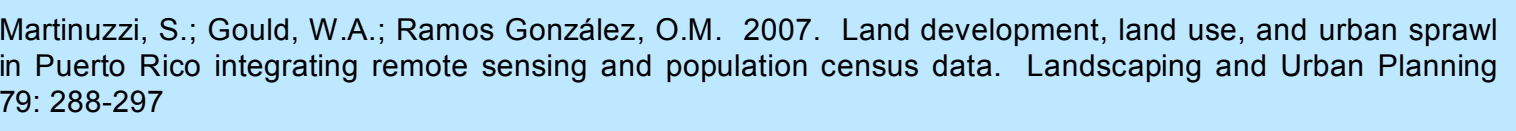

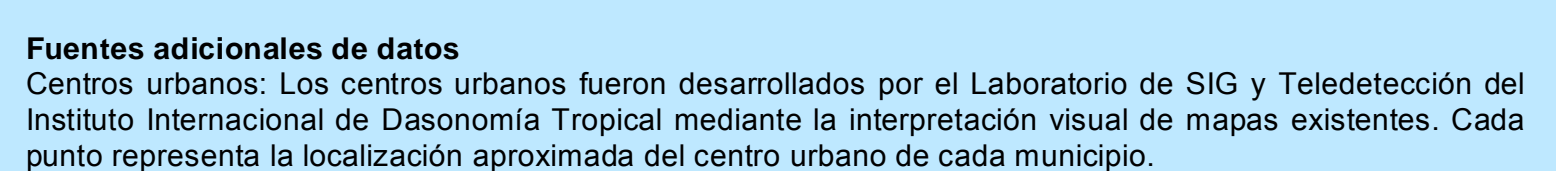

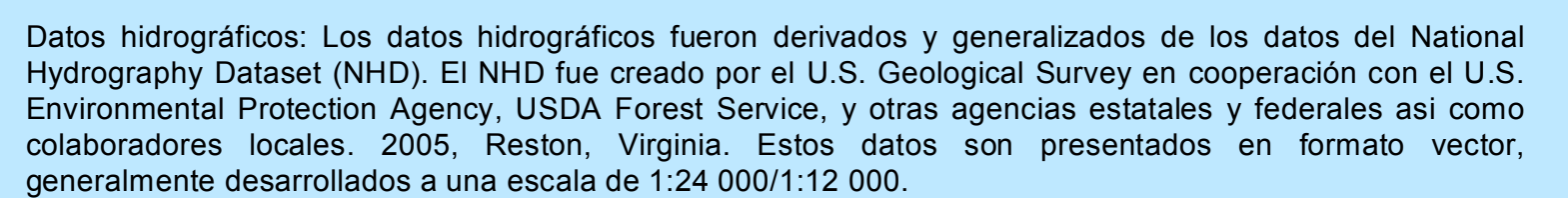

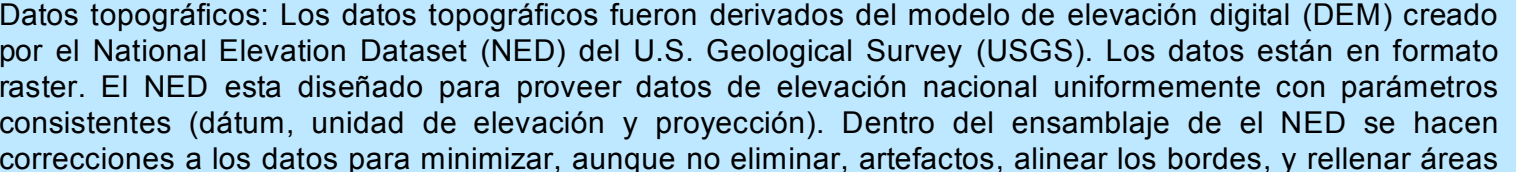

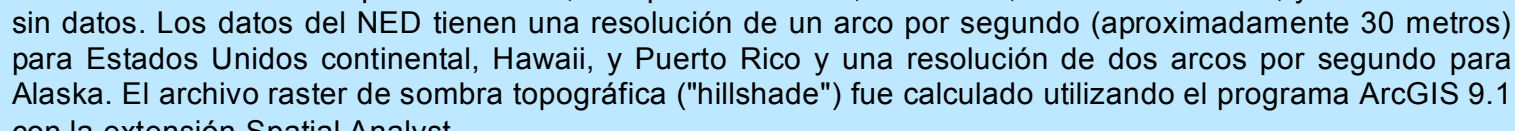

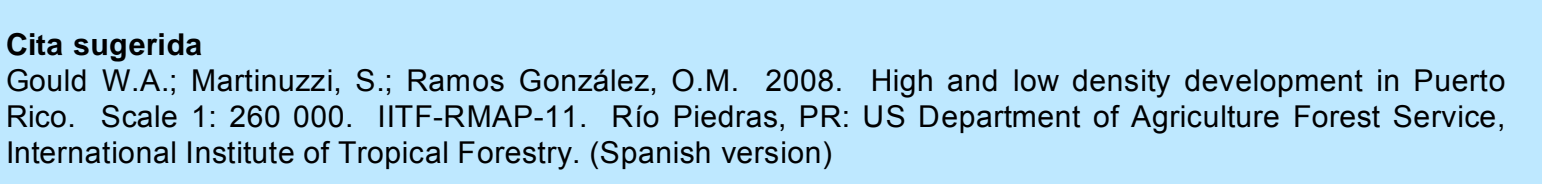

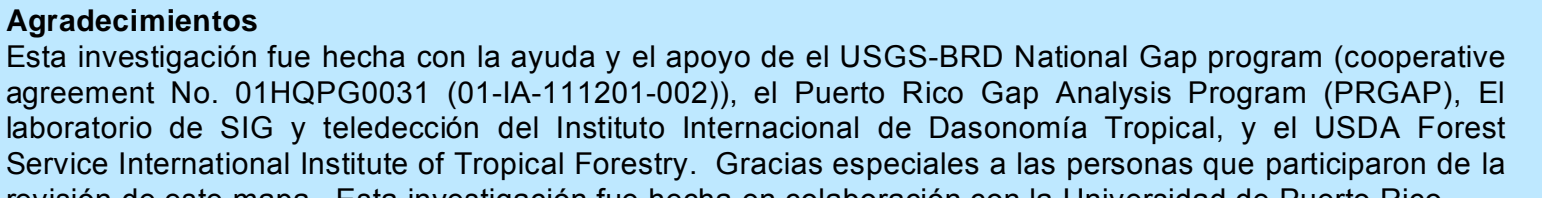

